\title{
Washback Effects of the New English Assessment System on Secondary Schools in Bhutan
}

\author{
ROBERT KIRKPATRICK \\ Gulf University of Science and Technology, Kuwait
}

\section{KINLEY GYEM}

Thailand

\begin{abstract}
Bio Data:
Robert Kirkpatrick has a Phd from Curtin University, and has spent over 17 years lecturing at universities in Asia. For the last five years he has been lecturing on the Master of Teaching as an International Language at Shinawatra Univeristy, and has now joined the English program at Gulf University of Science and Technology, Kuwait.
\end{abstract}

Kinley Gyem is a high school teacher from Bhutan and is now studying a Masters in education in Thailand.

\begin{abstract}
In 2006, Bhutan changed the secondary school curriculum. This study examines the washback effect of the English assessment system associated with this new curriculum. Based on questionnaire responses from 56 EFL secondary school teachers in Bhutan, the study suggests the new curriculum produces both positive and also negative washback. In order for the new curriculum's benefit to outweigh any harm it may cause, teachers should receive proper guidance and support during this transition.
\end{abstract}

\section{Introduction}

The Bhutan government champions the Gross National Happiness (GNH) index (Ura \& Galay, 2004) as being a cornerstone in Bhutan's development, and education embodies an essential path to the realization of that vision. In order to improve the quality of English education, which ostensibly increases happiness, a new curriculum was introduced in 2006 which offered new approaches of assessing students' language abilities.

This paper discusses the effects of the new education system, its curriculum, and the assessment systems and includes: (1) the history of Bhutanese education system and its policy goals, (2) a summary of the new English curriculum for secondary schools in Bhutan, (3) the washback effects of the new English assessment system on Bhutan secondary schools, and (4) recommendations on how to make the assessment more effective. 


\section{Background of the Bhutanese Education System}

Bhutan introduced Western-style education during the reign of the first king Ugyen Wangchuk (1907 - 1926). Since then, this approach remains the basis of most, if not all, developments and education reforms. During the First Development Plan (19611966), the most significant education reform was building additional schools. Doing so established a system offering free and modern education up to $10^{\text {th }}$ grade, and offering scholarships to top-performing studies to continue their studies.

Though Dzongkha is the national language, there is a trend toward using English and its usage in every domain is on the rise. In Bhutan, English is used in teaching for all subjects except for Dzongkha. Students undergo an examination to move from primary school to junior high, and another to graduate from high school. The Bhutan Board of Examination (BBE) is responsible for organizing and monitoring national examinations (i.e., All Bhutan Primary examination at the end of Grade VI and at the end of basic education program [Grade VIII] and at the end of Grade X and XII). The latter examination was conducted jointly with the Council for the Indian School Certificate Examinations of Delhi, but now it is solely administered by the BBE.

The Performance Management System (PMS) was introduced in Bhutan in 2010 as part of the Performance Compact signed by the education ministry. The compact sought to improve student outcomes, reduce repetition rates, promote GNH education, and enrich teacher satisfaction. It was intended to help attain Bhutan's goals of universal access and providing quality education. The PMS comprises three scorecards: (1) academic learning, (2) enabling practices in teaching and learning, and (3) achievements on GNH practices. Another new system to monitor quality of education over a period of time is being instituted called NEA.

\section{Secondary Education in Bhutan}

Secondary Education in Bhutan pairs general academics with vocational training. Lower Secondary School is a part of basic education and covers Grades VII and VIII. General higher secondary school includes two years of high school education (Grades IX and X), in all high schools, and two years of pre-university classes (Grades XI and XII), in selected high schools. According to the Center for Educational and Research Division (CERD, 2002) Bhutanese secondary school graduates should be competent in English with sound foundations in grammar and vocabulary; have developed critical thinking skills; and be well read in both fiction and non-fiction.

\section{Emergence of New English Curriculum for Secondary Schools in Bhutan}

The new English curriculum was developed by relevant officials from the Bhutan Board of Examination (BBE), the Education Monitoring Support Service Division (EMSSD), the Education Media Service (EMS), the Canadian Cooperation Office (CCO), the Department of Curriculum Research and Development (DCRD), and teachers and lecturers from schools and universities including two professors from the University of New Brunswick, Canada. Experts noted that at that time limited language skills, lack of child-centered and child friendly teaching-learning processes, improper assessment approaches, and low professional knowledge of teachers were hindrances to Bhutan's educational goals (DCRD, 2005-2006). 
There were scarcities and shortfalls in teaching, learning and the curriculum content of English. Previous English curriculum was one-sided with too much emphasis on literature - works are not necessarily practical and relevant to modern students. Assessment came from a single test administered at the end of the school year. Accordingly, teachers focused on explaining the literature texts to students and students spent all their time in writing down what the teacher said. This approach is firmly entrenched in schools. Teaching and learning of English had been condensed to the transmission of approved information about assigned literature texts and memorizing that information for examinations.

The new 2006 curriculum divides English into four key charters of learning: (1) speaking and listening, (2) writing, (3) reading and literature, and (4) language. Each charter has four parts - (i) statement of standard, (ii) indicators of levels of achievement, (iii) teacher engagement, and (iv) mandatory provisions. One commentator notes: "[t]he essence of the change is that students will be taught to develop skills in reading and writing, listening and speaking, grammar and language" (Wangmo K, 2005). However, possibly the most dramatic change is the introduction of continuous assessment (CA).

\section{Assessment System as Recommended by DCRD (2005-2006)}

Note $^{* *}$ : Detailed rationale, objectives, learning experiences, and student outcomes for the four strands are in Appendix 1. Question pattern and marking scheme are given in detail in Appendix 2.

\section{Modes of Assessment - CLASS XI \& XII}

Scheme of assessment as per the guidelines of DCRD (2005-2006):

- Continuous formative Assessment (CFA),

- Continuous Summative Assessment (CSA),

- Examinations,

- Mid-term examinations, and

- Annual Examinations

Continuous formative assessment. The Continuous Formative Assessment (CFA) test student core competencies. These assessments run a gamut from "handson" informal activities to standardized objective testing.

The primary aims of Continuous Formative Assessment (CFA) are to:

- provide opportunities to both the teacher and the learner to reflect on the learning process and on the level of achievement;

- help teachers to find out what teaching methods and materials work best

- help teachers pay attention to individual differences and learning styles of the learners;

- make learners realize how well they can do certain types of work and what they need to improve;

- enable learners to see the connection between efforts and results;

- allow the learners to evaluate themselves and also in peer group; 
- enable learners to take on multiple roles - as learners, helpers, evaluators and reviewers of the learning processes;

- enable learners to appreciate each other's talents and accept the weaknesses;

- develop and tap the higher level thinking and problem solving skills of learners;

The following are some of the suggested Continuous Formative Assessment activities:

- Ask series of questions to the class verbally;

- In pairs, provide opportunities for peer assessment among students;

- Provide students with the opportunities for individual self-assessment;

- Either in pairs or small groups, observe students and keep notes;

- In writing activities, focus on giving students enough time to absorb teacher critiques;

- Rubrics can be used for assessing students' writing, class participation, listening speaking and reading skills;

- Keep literacy Portfolios for both reading and writing activities; and

- Teachers could keep anecdotal records and notes for students as part of CFA, and follow the FA activities listed in teacher manuals. (Syllabus for classes XI and XII, 26) (DCRD, 2005-2006).

Continuous summative assessment. The Continuous Summative Assessment consists of the internal school-based assessment on the listening and speaking strand and two written examinations.

Internal assessment. The following are suggested modes of assessment for awarding internal assessment marks for Classes XI and XII:

Listening and Speaking - 20 marks:

Suggested listening and speaking activities assessments:

- Extemporaneous debate and public speaking,

- Panel discussions,

- Listening exercises, and

- Presentations and reports generally (Syllabus for classes XI and XII, 27)

\section{Paper I: Language and Writing}

Paper I consists of a writing portfolio and written examinations. The writing Portfolio includes reviews of assigned books and the best written pieces selected by the students on teacher's guidance, based on specific writing criteria. The portfolio is maintained for each student and must be assessed and awarded $20 \%$ marks as the part of CA. (Syllabus for classes XI and XII, 28)

Table 2.1

Suggested Weightings of Continuous Assessment and Examination

\begin{tabular}{|l|l|l|l|l|}
\hline \multicolumn{2}{|l|}{ TERM ONE } & \multicolumn{2}{l|}{ TERM TWO } & Total \\
\hline $\begin{array}{l}\text { Continuous } \\
\text { Assessment }\end{array}$ & Examination & $\begin{array}{l}\text { Continuous } \\
\text { Assessment }\end{array}$ & Examination & $100 \%$ \\
\hline
\end{tabular}




\begin{tabular}{|l|l|l|l|l|}
\hline $10 \%$ & $10 \%$ & $50 \%$ & \\
$\begin{array}{l}\text { Writing } \\
\text { Portfolio }\end{array}$ & $30 \%$ & $\begin{array}{l}\text { Writing } \\
\text { Portfolio }\end{array}$ & & \\
\hline
\end{tabular}

\section{Paper II: Reading and Literature}

Paper II assess a number of skills: (1) reading portfolio, (2) listening and speaking, and (3) written examinations. The reading portfolio includes (i) reading records, (ii) expository writing samples and critical responses, (iii) spoken discussion of books and core concepts, and (iv) book reviews. The listening and speaking sections include (i) listening exercises, (ii) reports and presentations, (iii) debates and extemporaneous speaking, and (iv) book discussion.

The reading portfolio carries $10 \%$, listening and speaking carries $10 \%$ and the written examinations (Term 1 and Term 2) are out of 80\% (Under the Research Paper). Students will learn simple steps or procedures in conducting a small action research. With teacher guidance, students will select their own topics and will write a research paper. The paper will be submitted after they complete grade XII. Assessment will be based on the students' substantive knowledge about action research, interviewing skills and questionnaire development skills.) (DCRD, 20052006).

Table 2.2

Continuous Assessment for Reading Portfolio, Listening and Speaking

\begin{tabular}{|l|l|}
\hline Reading Portfolio:10\% & Listening \& Speaking: 10\% \\
\hline - Record of reading & - Listening skills exercises \\
- Critical response to books read & $\begin{array}{l}\text { - Reports } \\
\text { - Text talk or book talk }\end{array}$ \\
& - Debates \\
& - Extempore speeches \\
& - Presentation of their written pieces \\
& Book talk \\
\hline
\end{tabular}

Table 2.3

Suggested Break up of CA and Examination Weightings

\begin{tabular}{|l|l|l|l|l|}
\hline \multicolumn{2}{|l|}{ TERM ONE } & \multicolumn{2}{|l|}{ TERM TWO } & Total \\
\hline $\begin{array}{l}\text { Continuous } \\
\text { Assessment }\end{array}$ & Examination & $\begin{array}{l}\text { Continuous } \\
\text { Assessment }\end{array}$ & Examination & \\
\cline { 1 - 3 } $\begin{array}{l}5 \% \text { Reading } \\
\text { Portfolio }\end{array}$ & \multirow{2}{*}{$30 \%$} & $\begin{array}{l}5 \% \text { Reading } \\
\text { Portfolio }\end{array}$ & $50 \%$ & $100 \%$ \\
\cline { 1 - 3 } 5 Listening \& & $5 \%$ Listening & & \\
\hline \hline
\end{tabular}




\begin{tabular}{|l|l|l|l|l|}
\hline Speaking & & \& Speaking & & \\
\hline
\end{tabular}

Note: The schools should conduct term one examination out of $100 \%$ and convert it to $30 \%$, similarly the term two examination should be conducted out of $100 \%$ and convert it to $50 \%$. By adding 20\% CA for Reading Portfolio and Listening \& Speaking strand to Paper II, the overall weighting will be 100\% (Syllabus for classes XI and XII, 29).

\section{Research Methodology}

The information was polled through a questionnaire. The teachers were emailed requesting their consent to participate in the study. The questionnaire was sent via email, and respondents were acknowledged through the same means. Among the seventy five teachers who were sent a questionnaire, a total of fifty six responded, achieving a response rate of approximately $75 \%$. These respondents were from different parts of Bhutan and represented secondary schools of various types, levels, and geographical locations. Eighteen of the participant teachers held master degrees in education with majors in English. The rest held bachelor's degrees in education (of whom twenty-two majored in English). Further, a set of questionnaire were administered as interview guideline questions with twenty recently graduated students (with graduation years either 2010 or 2011) who were assessed through the new English assessment system. The questionnaire was administered to try to determine the main washback effects.

The questionnaire covered the key areas including:

- Participant demographics;

- Views on new the English assessment system;

- Views on strengths and draw backs of the new assessment system;

- Challenges they encountered while implementing such a system

- Barrier factors included in the effective implementation of the new system;

- Overall washback effects they found both through on teaching and learning; and,

- Recommendations for best practices

The questionnaire included 24 questions for teachers and 9 questions for students. The questionnaire included objective, subjective, and open-ended questions (see appendix).

\section{Result of Data Analysis}

\section{Data Analysis}

Table 4.1

Survey Result of Teacher's Level of Opinion towards New English Assessment System

\begin{tabular}{|c|c|c|c|c|c|c|c|c|c|}
\hline \multirow{2}{*}{$\begin{array}{c}\text { Item } \\
\text { No }\end{array}$} & \multirow{2}{*}{ Statement } & \multicolumn{5}{|c|}{ Response frequency } & \multirow{2}{*}{$\begin{array}{c}\text { Response } \\
\text { Agreement } \\
(\%)\end{array}$} & \multirow{2}{*}{$\begin{array}{l}\text { Response } \\
\text { Dis - } \\
\text { agreement } \\
(\%)\end{array}$} & \multirow{2}{*}{$\begin{array}{c}\text { Response } \\
\text { Not sure } \\
(\%)\end{array}$} \\
\hline & & SA & A & NS & D & SD & & & \\
\hline
\end{tabular}




\begin{tabular}{|c|c|c|c|c|c|c|c|c|c|}
\hline 1 & $\begin{array}{l}\text { New English assessment system } \\
\text { on secondary schools in Bhutan is } \\
\text { effective }\end{array}$ & 24 & 22 & 2 & 5 & 3 & 82.1 & 14.3 & 3.6 \\
\hline 2 & $\begin{array}{l}\text { Teachers are given trainings } \\
\text { about new system of assessment } \\
\text { (short term, orientation, } \\
\text { workshop, seminars ) }\end{array}$ & 8 & 8 & 10 & 15 & 15 & 28.6 & 53.6 & 17.9 \\
\hline 3 & $\begin{array}{l}\text { Information from the workshop } \\
\text { or training are adequate enough } \\
\text { to implement the new system of } \\
\text { assessment in the school }\end{array}$ & 8 & 5 & 15 & 12 & 16 & 23.2 & 50.0 & 26.8 \\
\hline 4 & $\begin{array}{l}\text { There are adequate and sufficient } \\
\text { curriculum materials for } \\
\text { implementing new assessment } \\
\text { tools }\end{array}$ & 10 & 8 & 12 & 15 & 11 & 32.1 & 46.4 & 21.4 \\
\hline 5 & $\begin{array}{l}\text { New English curriculum and } \\
\text { assessment system are sufficient } \\
\text { for coverage in terms of time } \\
\text { allocation for both students and } \\
\text { teachers }\end{array}$ & 15 & 20 & 8 & 6 & 7 & 62.5 & 23.2 & 14.3 \\
\hline 6 & $\begin{array}{l}\text { My school strictly implements } \\
\text { the new assessment tools }\end{array}$ & 13 & 12 & 10 & 11 & 10 & 44.6 & 37.5 & 17.9 \\
\hline 7 & $\begin{array}{l}\text { I strictly follow the prescribed } \\
\text { assessment guidelines in } \\
\text { assessing my students' language } \\
\text { skills }\end{array}$ & 15 & 10 & 6 & 13 & 12 & 44.6 & 44.6 & 10.7 \\
\hline 8 & $\begin{array}{l}\text { My students can cope with the } \\
\text { new assessment methods }\end{array}$ & 6 & 12 & 20 & 15 & 3 & 32.1 & 32.1 & 35.7 \\
\hline 9 & $\begin{array}{l}\text { The objective of the new } \\
\text { assessment matches with the } \\
\text { skills of the student's assessment }\end{array}$ & 12 & 18 & 18 & 8 & 0 & 53.6 & 14.3 & 32.1 \\
\hline 10 & $\begin{array}{l}\text { New assessment system } \\
\text { motivates my students in } \\
\text { learning }\end{array}$ & 20 & 22 & 5 & 4 & 5 & 75.0 & 16.1 & 8.9 \\
\hline 11 & $\begin{array}{l}\text { New assessment system serves to } \\
\text { monitor and tract students' } \\
\text { performance }\end{array}$ & 22 & 25 & 5 & 3 & 1 & 83.9 & 7.1 & 8.9 \\
\hline 12 & $\begin{array}{l}\text { New assessment system helps me } \\
\text { to reflect on my teaching } \\
\text { methods }\end{array}$ & 18 & 25 & 10 & 3 & 0 & 76.8 & 5.4 & 17.9 \\
\hline 13 & $\begin{array}{l}\text { Standard of English language } \\
\text { skills of students in my school is } \\
\text { very good }\end{array}$ & 11 & 10 & 15 & 13 & 7 & 37.5 & 35.7 & 26.8 \\
\hline 14 & $\begin{array}{l}\text { Students are more enthusiastic in } \\
\text { learning English language skills } \\
\text { after the implementation of the } \\
\text { new system of assessment }\end{array}$ & 15 & 30 & 8 & 3 & 0 & 80.4 & 5.4 & 14.3 \\
\hline 15 & $\begin{array}{l}\text { Students have developed } \\
\text { positive attitude towards } \\
\text { literature after the } \\
\text { implementation of the new }\end{array}$ & 10 & 20 & 12 & 8 & 6 & 53.6 & 25.0 & 21.4 \\
\hline
\end{tabular}




\begin{tabular}{|c|c|c|c|c|c|c|c|c|c|}
\hline & system of assessment & & & & & & & & \\
\hline \multirow[t]{9}{*}{16} & \multicolumn{9}{|c|}{ Your opinion on the limitations of effective implementation of the new system: } \\
\hline & a) Lack of resources & 14 & 26 & 4 & 8 & 4 & 71.4 & 21.4 & 7.1 \\
\hline & $\begin{array}{l}\text { b) Large number of students in } \\
\text { the class }\end{array}$ & 40 & 8 & 5 & 2 & 1 & 85.7 & 5.4 & 8.9 \\
\hline & $\begin{array}{l}\text { c) Heavy workload on the } \\
\text { language teachers }\end{array}$ & 30 & 15 & 8 & 3 & 0 & 80.4 & 5.4 & 14.3 \\
\hline & $\begin{array}{l}\text { d) Summative tests scores for } \\
\text { promotion }\end{array}$ & 35 & 13 & 0 & 5 & 3 & 85.7 & 14.3 & 0.0 \\
\hline & e) English taught in isolation & 25 & 18 & 5 & 3 & 5 & 76.8 & 14.3 & 8.9 \\
\hline & $\begin{array}{l}\text { f) Lack of monitoring and } \\
\text { support services }\end{array}$ & 16 & 18 & 10 & 12 & 0 & 60.7 & 21.4 & 17.9 \\
\hline & $\begin{array}{l}\text { g) Lack of assessment literate } \\
\text { teachers }\end{array}$ & 25 & 15 & 5 & 6 & 5 & 71.4 & 19.6 & 8.9 \\
\hline & $\begin{array}{l}\text { h) Generous assessment done } \\
\text { by teachers }\end{array}$ & 12 & 15 & 9 & 15 & 5 & 48.2 & 35.7 & 16.1 \\
\hline 17 & $\begin{array}{l}\text { The new assessment system is } \\
\text { fair and equitable }\end{array}$ & 15 & 21 & 10 & 5 & 5 & 64.3 & 17.9 & 17.9 \\
\hline 18 & $\begin{array}{l}\text { The new assessment system focus } \\
\text { more on the students' needs and } \\
\text { preferences }\end{array}$ & 15 & 21 & 10 & 5 & 5 & 64.3 & 17.9 & 17.9 \\
\hline 19 & $\begin{array}{l}\text { The new assessment system } \\
\text { adapts new strategies of teaching }\end{array}$ & 18 & 21 & 12 & 5 & 0 & 69.6 & 8.9 & 21.4 \\
\hline 20 & $\begin{array}{l}\text { The new assessment system } \\
\text { serves to Identify the strength } \\
\text { and weaknesses of my teaching }\end{array}$ & 25 & 15 & 10 & 6 & 0 & 71.4 & 10.7 & 17.9 \\
\hline 21 & $\begin{array}{l}\text { The Ministry of education } \\
\text { monitors the effectiveness of new } \\
\text { assessment in schools from time } \\
\text { to time }\end{array}$ & 10 & 8 & 6 & 12 & 20 & 32.1 & 57.1 & 10.7 \\
\hline 22 & $\begin{array}{l}\text { There is continuity in the } \\
\text { implementation of new } \\
\text { assessment system through all } \\
\text { grades from lower to higher in } \\
\text { assessing student's language } \\
\text { learning }\end{array}$ & 14 & 11 & 6 & 10 & 15 & 44.6 & 44.6 & 10.7 \\
\hline
\end{tabular}




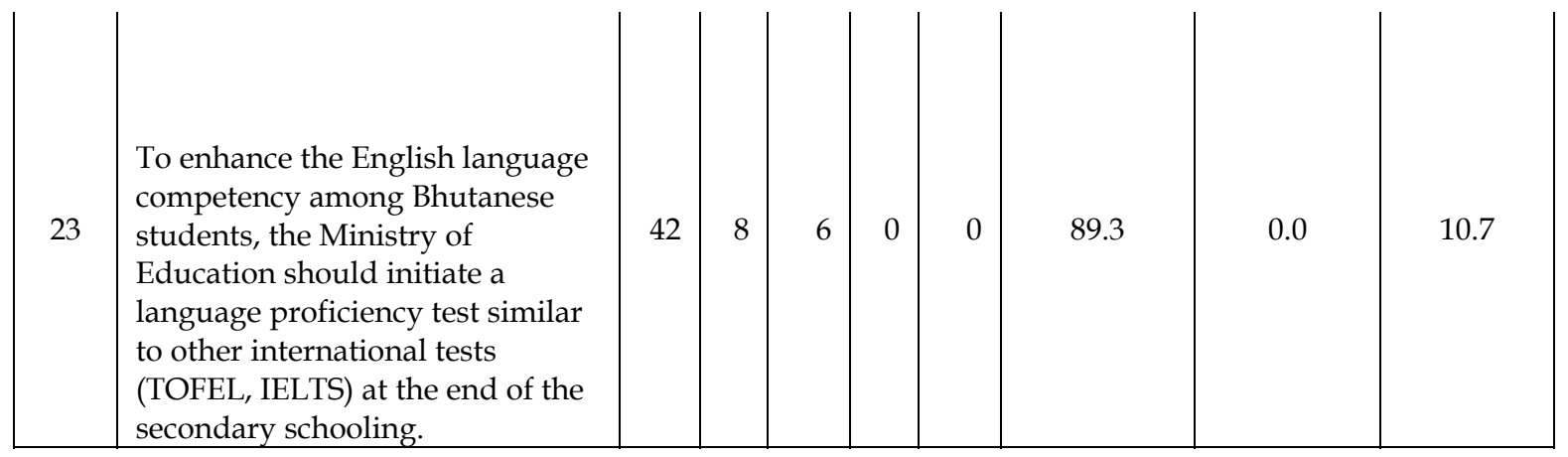

\section{Positive Washback Effects}

As anticipated by curriculum designers, the new approach delivered some positive results. Though a recently-adopted system, teachers were quick to accept new approaches to teaching. The respondents of the study shared some of the positive results. The majority of the respondents accepted the fact that the best thing about the implementation of the new system is that now the assessment is seen by teachers and students as a fundamental part of the entire teaching and learning process.

Students receive explanatory and diagnostic feedback as well as grades. They were also offered provisions for student choices in assessment tasks, and also the tasks were checked to confirm there were no inherent prejudices that may disadvantage any particular student group. They realized that such tasks consider the capacity to examine and blend new information and ideas rather than merely recall information previously presented. The majority of respondents from both teachers and students claimed that the various roles of assessment are known.

As the assessment is subjective by necessity to a certain extent, educators should agree on a concrete assessment strategy. Fortunately, the new teacher's guide contains the criteria, rubrics, and checklist samples for teachers to adopt. Teacher respondents noted that a well-designed rubric helps teachers provide detailed and unbiased student assessments. Additionally, teachers need to be trained to apply the rubrics consistently. The teachers shared that they employ a diversity of assessment approaches so that the limitations of certain methods are discouraged. Assessment tasks are weighted to balance the formative and summative roles of assessment.

The majority of the student respondents accepted that they studied more effectively when they were aware of the assessment styles. They also valued and expected transparency in how their knowledge would be assessed. They also wanted to comprehend how grades were determined and they expected timely feedback. Thus, the students became more and more motivated about their education. In the meantime, they also preferred their comprehensive test to be in the pattern of international language proficiency tests like TOFEL, ILTS, and the like. Both teachers and students admit that the current assessment method works well.

\section{Negative Washback Effects}

Approximately $60 \%$ of respondents shared their concerns for the vagueness of the methodological approaches; possibly resulting in negative washback effects.

Some implications that weigh against the effective implementation includes:

- The content of the syllabus mismatches with the time allocated to study; 
- There is not a steady progression in the intricacy and demands of assessment requirements in the later years of studies;

- It places huge workloads on both students and teachers, which distracts from the effective implementation of the system; and

- a tendency towards grade inflation.

\section{Factors Resulting in Negative Washback}

As listed in the table 4.1, the most prevalent negative washback effects were:

- Lack of specific training: In the areas that they argued it was necessary to make the effective implementation. They expressed that they were expected to understand everything from the teachers'-guide that they have. It would have been much more effective if they were at least given a short course.

- Lack of curriculum materials: Since the curriculum materials were not enough, the implementers faced the difficulty in getting more insights into how to carry on the assessment system more effectively.

- Crowded classes: The minimum strength of students in the class is 35, resulting in the impossibility of carrying out the assessment as prescribed. The young age of students and cramped classrooms with mixed ability could have a lot to do with the failing of the current assessment system implementation. Most of the respondents agree.

- Isolation: English is taught in isolation. Most regard English as a subject in and of itself, rather than a way that facilitates learning and expression in other subjects as well.

- Lack of monitoring and support: EMSSD officials failure to monitor the assessment practices in schools leads to the relaxation of effective assessment practices or wrong practices: which could also miss the required support and feedback on how to make the implementation of such a practice successful.

- Summative assessment: Both teachers and students still focus on ensuring on passing the final exam

- Heavy workload: Since the workload to implement these new procedures is heavier increases for teachers - particularly ones teaching English - face difficulties in coping with the practice.

- Lack of assessment literate teachers: Most teachers are not sure or have very little knowledge about the new assessment system; they are not competent and skilled enough to carry out the assessment practices as desired.

\section{Discussion}

There is widespread public concern regarding waning quality education. This is particularly so for English language education. This unease forced the Ministry of Education to focus on reforming English curriculum in the Bhutanese education system. If implemented properly, the new assessment system will allow teachers the resources to objectively assess student performance individually.

Apparently, effective language assessment offers material for reflecting on teaching efficacy, appreciation of learners' learning tactics and learning hitches, and design or revision of teaching styles or methodologies. The current method would enable students to read and understand and interpret language and writing 
individually. This will help them assess their skills as individual learners. In the meantime, one must take into considerations to design any assessment system with the expectation that it will help classroom teachers to keep a better balance between teaching and skill building, on the one hand, and examination preparation on the other.

\section{Recommendations}

To ensure positive washback effects of new English assessment system the major recommendations suggested from the findings are:

1. Curriculum: should draw examples from the local surroundings as well as global ones. Related topics should be linked with what is taught in the previous level. Discontinuity of the syllabus between classes confuses teachers in keeping the track of students' progression while assessing. It also confuses student on focusing and improving their proficiency. Parts of curriculum focused too much on writing, should have a balance across all the four skills so as to balance the assessment weightage on four skills.

2. Professional development: More professional development for teachers in teaching English (pedagogy) and subject knowledge. English teachers should be given specific training on how to make the new assessment system work effectively. Identify master/lead teachers and offer training and other learning opportunities specifically on English Language Assessment on secondary schools.

3. Align summative and formative assessment approaches: Both approaches to assessment are equally important.

4. Pre-service: Align pre-service with the revised curriculum by having at least one course entirely focused on testing and assessment. This could well equip the preservice teachers with the skills and knowledge of testing and assessment. Thus, the ministry should revisit the curriculum for pre-service teacher's course and then make necessary changes.

5. Assessment tasks: There are also excessive assessment tasks. They should be focused on quality assessment and designed to sample student learning.

6. School level faculty: There should be a faculty/departmental policy that guide individuals' assessment practices. The faculty member should guide the teachers in carrying out the assessment effectively and at the same time monitor to make sure the departmental policy is followed.

7. Authentic tasks: Students prefer assessment tasks they perceive to be authentic. Thus they recommend tasks that present challenges to be taken earnestly, not only for the grades, but also those they believe to mirror the skills needed in the work place.

8. Curriculum materials: Provide enough curriculum materials e g. teacher guides and assessment procedures on time.

9. Monitoring and support services: Provide proper monitoring and support services to the schools by concerned department. Reinforce effective assessment and evaluation system in the examination procedures.

10. Language across the curriculum: Since English language is the medium of instruction for all other subject accept Dzongkha, it is also the medium for the reception and expression of knowledge. Language teaching and assessment should 
not be solely left on language teachers, but should also be taken into account by other teachers as well throughout the curriculum.

\section{Conclusion}

A paradigm shift is taking place in Bhutan's education system. There are many challenges as teaching and learning in Bhutan are by tradition deep embedded in the transmission model in which teachers are the key source of knowledge and authority and students are at the receiving end. Despite the fact that English is studied through twelve years of their education - starting from age six and continuing until graduation from high school at age eighteen - many learners struggle using language. Thus, it would appear that the primary objectives of the syllabus prescribed by DCRD, remain, as of yet, largely unfulfilled.

Curriculum affects language education. There should be good balance between both summative and formative assessment. Summative tests are important, but formative assessment is productive in assessing and expanding knowledge. There is no doubt that the new assessment system brought some changes and improvement in teaching and learning in secondary schools in Bhutan. However, it has become evident that language teaching and assessment are not meeting the academic, workplace and development needs of contemporary Bhutan. Perhaps, the language tests concentrate on linguistic items and fail to assess effectiveness in the use of the language.

The inadequacy of curriculum materials, assessment literate teachers, and exam score-based for student's promotion are most pivotal factors that limits the positive washback effects on both teaching and learning outcomes in secondary schools in Bhutan. In addition, there are insufficient specialists and programs for diagnosing and indentifying learners with special needs or special needs of students so that they could be attended early in the learning process.

By the year 2006, the DCRD completed redesigning and validating the English curriculum along with its assessment system with the intention of improving teaching and learning practices. Intentional actions towards positive washback require, as some English language teachers have recommended, congruity between assessment and curriculum related objectives, authenticity of tasks, detailed score reporting, teachers' understanding of the assessment criteria, and learner selfassessment. The findings indicate that even though teachers are provided with the guidelines to effective assessment practice provided by DCRD, they seem to be reluctant to use the state rubrics, descriptors, and checklist samples. With this it can be assumed that there may be some deficiencies in the support materials that the teachers may be using their own assessment tolls, or they are not adopting the suggested assessment approach.

It seems from the study that many teachers have being unable to successfully implement the new assessment system as established by DCRD. Diverse issues may account for this: when innovative assessment is projected it may take teachers some time to adjust to changes. It is likely that some aspects of the assessment system are not yet internalized or clear to teachers. Therefore, the concerned department needs to offer more training opportunities and stimulus that will motivate teachers to participate in the assessment process in a more committed manner. 
While the introduction of new English assessment to education is a positive development, there are still issues and problems facing teachers, students and policy makers. It is intended that this small study bestow some insight to this aspect of new English assessment on secondary schools of Bhutan. 


\section{Reference}

Anderson, L. W. (2004). Increasing teacher effectiveness. Paris: UNESCO.

Black, P., \& William, D. (1998). Assessment and classroom learning. Assessment in Education, 5(1), 7-74. Retrieved from http://www.tandfonline.com/doi/abs/10.1080/0969595980050102,

Bruyn, J. D., Brown. J., Messenger, W. E., \& Montagnes, R.,(2005). The Canadian writer's handbook (4th ed.). Canada: Oxford University Press.

Cheng, L. (1998). Changing assessment: Washback on teacher perceptions and actions. Retrieved from

http://www.clal.org.cn/personal/testing/washback/cheng1999(washback). pdf,

Christopher, N. M. (2008). Social and educational imapct of language assessment in Nigeria. Nordic Journal of African Studies. 17(3), 198-210.

Department of curriculum research and development. (2005-2006). Retrieved from http:/ / www.curriculum.bt/index.php/syllabus/class-11-12.html, 252012.

Dunn, K. E., \& Mulvenon, S. W. (2009). A critical review of research on formative assessment: The limited scientific evidence of the impact of formative assessment in education. Practical Assessment, Research and Evaluation, 14(7), 211.

Kiomrs, R. (2011). On the interaction of test washback and teacher assessment literacy: The case of Iranian EFL secondary school teachers. English Language Teaching, 4(1), 23-35.

Leung, C., \& Mohan, B. (2004). Teacher formative assessment and talk in classroom contexts: Assessment as discourse and assessment of discourse. Language Testing, 21(3), 335-359. Retrieved from http:/ / ltj.sagepub.com/content/21/3/335.abstract

Standards for English for schools in Bhutan. (2002). The silken knot: Standards for English for schools in Bhutan. Centre for Educational Research and Development (CERD): Paro.

Syllabus for classes XI and XII. (2007). Mode of assessment for class XI and XII, English. CAPSD and BBE: Thimphu.

Ura, K., \& Galay, K. (Eds.) (2004). Gross national happiness and development. Thimphu: Center for Bhutan Studies.

Wangchuk, L. (2008). Facts about Bhutan: The land of the thunder dragon. Thimphu: Absolute Bhutan Books.

Wangmo, K. (2005). New English curriculum. Kuensel, p. 1-2.

\section{Appendix 1}

\section{READING \& LITERATURE STRAND \\ Rationale}

Literature embodies an experience of life expressed in a language that appeals. Literature reflects and expresses the human imagination. It brings understanding and enrichment to readers' lives.

Through the study of literature, students learn to respond to ideas, issues, perspectives and actions of others more critically and analytically. It also enables 
students to understand the structure and intent of a variety of literary forms. At this level, students must learn to explore the techniques used by authors to convey messages, persuade and influence, evoke responses and feelings and connect literature to their own lives and daily experiences. The literature in the syllabus provides the material to teach students how to read, while at the same time permitting them to read some of the best literature available in English. Students have to learn how to make meaning by themselves and to have met some of the best writers and their works in the course of their studies. If we can build classroom communities where that can be arranged, our readers will be drawn to travel through new worlds of experience whose horizons keep expanding.

\section{Aims}

The English literature course aims to help students to:

1. Read with fluency and confidence.

2. Evaluate how authors achieve their effects by the use of linguistic, structural and presentational devices - point of view, figurative language, flashback, parallel argument, and symbol and image patterns.

3. Select and analyze information from a variety of texts to support their responses.

4. Demonstrate an increased familiarity with major writers and their works.

5. Show genuine interest in reading.

6. Come to new understanding of the human condition - what it is like to be in love, struggle with notions of spirituality, and the death of loved ones.

7. Show a deepened sense of justice and fair play.

\section{Learning Experiences}

Through the study of literature, students will:

1. Gain exposure to different types of literary texts.

2. Prepare speeches for public performance; stage plays; and produce radio scripts and computer presentations.

3. Continue to use the reading strategies learned at each of the earlier levels as they read a wide range of texts, fiction and non-fiction.

4. Select, analyze, and synthesize information from a variety of sources to develop and support their responses to texts.

5. Understand and evaluate how authors achieve their effects in their writing with the use of linguistic, presentational and structural devices, point of view, flashback, figurative language, parallel arguments, and image and symbol patterns.

6. Synthesize information which they collect from other sources to support their views about major writers and their works.

7. Read, talk about and write about the works of major writers.

8. Reflect and engage regularly in debates and discussions about the ideas and values, such as beauty and truth as discussed in major literary works.

\section{Learning Outcomes}

As a result of these learning experiences students will be able to:

1. Read fiction and non-fiction texts with fluency and confidence using the features and purposes of different kinds of texts as a strategy for making meaning. 
2. Analyse how authors achieve their effects by the use of linguistic, structural and presentational devices - points of view, figurative language, flashback, parallel argument, symbols and image patterns - and use this information to make meaning with the text.

3. Select and analyse information from a variety of texts to support their points of view.

4. Come to a new understanding of the human condition through their readings the notions of spirituality, love, understanding, impermanence, tolerance, patriotism, the impact of modern technology, aging, self-knowledge, and language and culture.

5. Demonstrate a heightened sense of beauty and harmony.

6. Assess their own values in the light of what they encounter in the literature they study to enrich their personal, cultural, and national beliefs.

7. Talk and write about Bhutanese writers as well as major classical and modern writers and their works.

8. Distinguish the best pieces of literature and make choices for their personal collection.

\section{LANGUAGE STRAND}

Rationale

Every living being strives to communicate with its own kind. One of the ways in which this need is fulfilled is by expressing thoughts in the medium of language. Language is the bridge between individuals that tells them they are needed, that they are not alone. Language thus gives us self-expression and, by extension, identity. It gives shape to thoughts and emotions, and communicates these to intended audiences. It is the basic element with which the history of the world has been recorded. It is a time capsule that allows us to view and re-view any moment in the past of literate man. It is a repository of information that envelops all recorded knowledge and so acts as a gateway to development. It allows peoples of the world to understand different cultures as well as belief systems, and to share ideas. In this regard, no other language has proved more useful than English.

Proficiency in English is therefore seen as a necessity in both academic and professional life. The proper study of English entails detailed study of grammar and conventions of usage, along with other language competencies (listening, speaking, reading, and writing). In Bhutan where English is used as a second language and students use English frequently only in school, it is of utmost importance that our students receive direct teaching in the grammar, pronunciation and syntax of English in a consistent, thorough, and interactive manner.

\section{Aims}

The language course aims to help students to:

1. Use grammatical conventions with accuracy and confidence

2. Use syntactical patterns with accuracy.

3. Select appropriate language to express concrete and abstract ideas.

4. Demonstrate the use of a sophisticated vocabulary and expression.

5. Show an awareness of the common theories of language acquisition and development. 
6. Discuss some of the characteristics features of human language.

\section{Learning Experiences}

Through the study of Language, students will:

1. Engage in activities and discussions in which they try to imagine a world without language; invent a language of their own; take advantage of the multi-lingual nature of Bhutanese classrooms to show how the same idea can be expressed in different languages and structures.

2. Engage in activities in which they practise language for formal and informal situations; discussions on the use of slang; to arrive an understanding of how a language changes over time to meet new demands particularly language that is sensitive to gender and age.

3. Explore the relationship between language and grammar.

4. Learn the conventions of standard English.

5. Students will practise English sounds; examine the structures in which sounds appear - letter, syllable, word, sentence, paragraph - to hear the changes each structures brings to sounds in the light of intonation, vocality, and context.

6. Students will learn standard English word order and how it differs from the other languages they speak. Teachers need to take advantage of the fact that students speak several languages to show how language works.

\section{Learning Outcomes}

As a result of these learning experiences students will be able to:

1. Know and use transitive and intransitive verbs appropriately.

2. Use literal and figurative language appropriately.

3. Use the dictionary to find out the number of syllables in a word and the stress given to each syllable.

4. Know and distinguish archaic words, derogative, slang and obsolete language and know when to use them appropriately.

5. Discuss the origin of words (etymology) and how they become a part of the language or how they become obsolete.

6. Know and discuss the common theories of language acquisition and development, for example, the opposing theories that language is innate versus language is acquired.

7. Know and discuss some of the characteristic features of human language, for example, that it is diverse and has common features such as fixed word order and grammar; that it reflects the culture of people who use it; that it is a means of communication, and is a way to express creativity.

8. Discuss the purposes of language.

\section{WRITING}

\section{Rationale}

The capacity of human beings to write down what they have thought, dreamed of and spoken about makes their language abilities unique. Thoughts expressed in writing can take on a life of their own. They can continue to engage the reader in discussions about ideas long after the writer has departed. 
Writing is a way of thinking and learning. It is a process with which thoughts are refined and the language in which they are written made more precise. Writers draft what they want to say. That first draft is a rehearsal of the ideas and the structures in which they have chosen to present them. They will go on to draft and redraft their ideas in writing, to edit them, modify them after they have shared their ideas with their colleagues, and polish their language, until they arrive at a concise statement of what they want to say. Out of this matrix of thinking, drafting and redrafting, editing and modifying, emerges an understanding of the topic, which is much clearer and more precise than when the writers began. Now when the writers engage in conversations or debates on the topic, they can contribute to the discussion in concise ways. Writers write for many different reasons. There is a need to write to friends. There are other kinds of personal writing as well. Journals, diaries, notebooks, wishes and dreams are written down for the writer alone to read. Writers write to do business with people whom they do not know. They write to explain their research to colleagues whom they have not met; to argue a position, to try to persuade people whom they do not know to accept their services. Writers write to delight their readers with imaginary people, lovable animals characters and worlds different but similar to their own.

Students need to practise so that they develop their abilities and skills in each of these kinds of writing, the personal, the transactional and the creative or poetic. They have to be exposed to the stages of writing and to the many strategies that writers use to make their writing say what they want it to say. Students will find tactics that work for them and incorporate these into their repertoire of writing strategies. They will discover that certain strategies work better for specific writing tasks while others work for them almost all the time. As they write they become more aware of their own writing processes, they will take control of their writing and become effective writers.

\section{Aims}

The Writing course aims to help students to:

1. Use vocabulary and grammar to make fine distinctions and achieve emphasis.

2. Show a clear grasp of the use of paragraphing and punctuation.

3. Write non-fiction that is coherent and gives clear points of view.

4. Write fiction that shows control of characters, events, settings and uses a variety of structures.

5. Write poetry that shows control of the different forms.

6. Take notes and prepare reports from their notes.

7. Demonstrate a clear understanding of the criteria for good writing.

8. Use the writing process effectively and build their portfolio.

\section{Learning Experiences}

Through the study of Writing, students will:

1. Write regularly for a wide range of purposes, not only to answer questions posed by the teacher.

2. Use the writing process. 
3. Study examples of good writing selected from the general categories of fiction and nonfiction, which illustrate good models in each of - personal, transactional and poetic writing.

4. Present their writing publicly to a variety of audiences - classmates, schoolmates, parents and other groups.

5. Build a portfolio of their best work in each of poetic, personal and transactional writing.

6. Evaluate their own writing using the criteria for good writing.

7. Help with the editing of the work of their fellow students.

8. Have fun as they create their own work to entertain, inform and delight others.

\section{Learning Outcomes}

As a result of these learning experiences students will be able to:

1. Write a short story in which they show control of the elements of the short story form.

2. Write an expository essay.

3. Write an argumentative essay.

4. Write lyric poetry in the modern idiom, which uses contemporary ideas of language, cadence, and image.

5. Begin and complete a research paper in which they show understanding and control of the conventions of academic writing.

6. Respond in writing to examination questions and homework assignments at an acceptable level.

7. Know the purposes and structures of the texts they are studying in Reading \& Literature and use them in their writing.

8. Explore personal, cultural, and national beliefs in their writing.

9. Demonstrate that they can make fine distinctions in grammar and diction to achieve precision in their writing.

10. Complete and present their portfolios which contain their best examples of personal, transactional, and poetic writing.

\section{LISTENING \& SPEAKING STRAND}

\section{Rationale}

We are born into the world capable not only of speaking any language but also capable of listening to the language that we hear around us so that we can learn how to use it to communicate our thoughts and feelings. As we listen, we acknowledge the presence of people around us and learn to make sense of the sounds they make. The practice of the skill of listening, and the growing necessity to express what we need, think, feel and understand, leads us naturally to learn to use the spoken world. To listen well is a skill that assists us in all aspects of our relationships with others. To listen with empathy allows us to share both messages and feelings. To listen well is to honour the thoughts of others and accept their contributions to the well being of our community. To listen well is to learn new ideas and perceptions, words and structures. To listen is to learn from good speakers their skills at rhetoric and gesture so we can use them for ourselves when we speak. 
To speak is an art which we all practice. It is one of the important ways by which people know us. To learn to do it well gives us confidence in ourselves and gives others confidence in us. We need to learn to speak with ease and clarity so that we can, as people in the workplace, members of family, and citizens in our communities make contributions to the common good. Conversations of all kinds sharpen our understanding. They draw us closer, fulfilling the need for companionship as we share what we understand about what it is to be human.

In sum, we listen and speak for a variety of purposes on both formal and informal occasions.

Whatever the circumstance, we need to learn to listen and speak well. The skills of Listening and Speaking is to be taught directly and practiced so that we become better at using them to help us in our quest for understanding the world we live in.

\section{Aims}

The Listening and Speaking course aims to help students to:

1. Demonstrate an apt use of vocabulary.

2. Use language that is accurate in grammar and free from errors in pronunciation.

3 . Lead routine meetings and manage interactions in small groups.

4. Make a range of contributions which show that they have listened perceptively to the development of a discussion.

5. Explain their position on and understanding of complex issues.

6. Maintain and develop their talk purposely in a range of contexts.

7. Participate in a variety of contexts, public or otherwise, using appropriate intonation and emphasis.

\section{Learning Experiences}

Through the study of Listening and Speaking students will:

1. Have regular and consistent practice in pronouncing sounds, words and sentences.

2. Engage in purposeful conversations, dialogues, and informal debates regularly.

3. Respond respectfully to those who express views different to their own.

4. Practice in building on the talk of others and modifying ideas through conversation.

5. Listen to examples of good oral presentations as they are delivered, either live or on tape, which demonstrate a range of purpose and tone.

6. Practise recounting and commenting on what has been listened to.

7. Practise speaking and listening regularly in small groups, first on simple topics and then gradually on more complex issues and themes.

8. Listen for signals that indicate a speaker's tone, intent and message

9. Learn tone, language and messages which are appropriate for different audiences and purposes.

10. Participate as members of small task groups and then leaders of those groups, to learn language and behaviour appropriate to these roles.

11. Observe appropriate body language which accompanies formal and informal speech acts. 
12. Build their own speeches for use in public.

13. Speak in public for various purposes: debates, explanations, reports, advertisements, eulogies, introduction of visitors, toasts at parties, responses to questions from an audience.

\section{Learning Outcomes}

As a result of these learning experiences students will be able to:

1. Speak using correct question tag.

2. Talk about major classical and modern writers (including Bhutanese writers) and their works.

3. Organise and participate in a panel discussion.

4. Use public speaking skills such as conventions of address, methods of introduction of a topic or theme, timing, pace, tone, intonation, gestures and closure to speak effectively in different contexts.

5. Listen to and gather information from different kinds of oral presentations.

6. Analyse different kinds of speeches and use them as models for their own.

7. Deliver speeches incorporating literary quotations, allusions, and imagery.

8. Use negotiation skills to resolve diplomatically conflicts that arise among members of groups.

9. Speak with clear pronunciation.

\section{Appendix 2}

\section{Question Pattern \& Marking Scheme}

There will be two papers for the Examination. Paper I will consist of Language and Writing strands. The time allotted for the written examination is as given below:

\section{Time: 3 hours for writing and 15 minutes for reading the questions} Weighting: 100marks (60 marks for writing and 40 marks for Language) Question Format:

The Paper I will have two sections-Section A and Section B.

\section{SECTION A}

Section $\mathrm{A}$ is for Writing and it will be marked out of $60 \%$. This section will test students' writing skills through extended response questions. This section will have two questions.

\section{Question 1:}

Students are required to choose and write persuasive essay from the three choices provided. It will be worth 25 marks.

\section{Question 2:}

Students are required to write any original work and demonstrate their understanding of how to create character, establish setting, develop a plot and show that they can handle the elements of short stories. It will be worth 30 marks.

\section{SECTION B}

The questions under section B will test students' language skills through short answer questions. 
It will be worth 40 marks.

\section{Question 1:10 marks}

The students will be examined on their understanding of origin of words (etymology) and common theories of language acquisition.

\section{Question 2: 30 marks}

There will be questions on grammar which will require students to correct, rewrite, edit, and complete sentences. It will be worth 30 marks.

\section{Examination weighting for:}

Writing

Essay $30 \%$

Story Writing 30\%

Language

Nature of Language $10 \%$

Grammar Structure 30\%

Total 100\%

The second part is the written examination on the Reading \& Literature strand. The time allotted for the written examination is as given below:

Time: 3 hours for writing and 15 minutes for reading Weightings:

Short Stories: 25 marks

Essay: 25 marks

Poetry: 25 marks

Novel: 25 marks

Question Format:

In Paper II there will be four sections as shown below:

Section A: Short Stories

Section B: Essay

Section C: Poetry

Section D: Novel

In each Section there will be two sets of questions of which either set I or set II to be attempted. However, students must attempt at least one set II (Extended Response) questions from any of the four sections.

\section{Assessment Scheme and Question Pattern:}

\section{Section A: Short Stories}

Set I: 25 marks

Multiple Choice Questions - 5 marks

Short Answer Questions - 20 marks

Set II: 25 marks

Extended Response Questions - Two questions: $10+15=25$ marks

Note: In section A questions will be set on seen texts.

Section B: Essay

Set I: $\mathbf{2 5}$ marks

Multiple Choice Questions - 5 marks

Short Answer Questions - 20 marks 


\section{Set II: 25 marks}

Extended Response Questions - Two questions: 10+15=25marks

Note: In section B questions will be set on unseen texts.

\section{Section C: Poetry}

Set I: 25 marks

Multiple Choice Questions - 5 marks

Short Answer Questions - 20 marks

Set II: 25 marks

Extended Response Questions - Two questions: $10+15=25$ marks

Note: In section C questions will be set on unseen texts.

\section{Section D: Novel}

Set I: 25 marks

Multiple Choice Questions - 5 marks

Short Answer Questions - 20marks

\section{Set II: 25 marks}

Extended Response Questions - Two questions: 10+15=25marks

Note: In section D questions will be set on seen text.

In each genre, the questions will test the students' ability to:

- Understand the text

- Give relevant interpretations of the contents in their own words

- Identify elements, points of view, themes, ideas, and analyse, synthesize, evaluate the texts and apply the ideas.

\section{Appendix 3}

\section{Survey Questionnaire for teachers}

Wash back effects of the new English assessment system on secondary schools in Bhutan

Part A: Demographic Information of the respondent

Gender: Qualification:

1. Type of school you are teaching:

Higher secondary

Middle secondary

Lower secondary

2. No of years of teaching experience:

Part B: Respondent Opinion

Please tick [ ] the level of your opinion (from strongly agree to strongly disagree) towards each statement. Please put only one tick for each statement.

\begin{tabular}{|l|l|l|l|l|l|l|}
\hline S1. No. & Statement & $\mathbf{5}$ & $\mathbf{4}$ & $\mathbf{3}$ & $\mathbf{2}$ & $\mathbf{1}$ \\
\hline 1 & $\begin{array}{l}\text { New English assessment system on } \\
\text { secondary schools in Bhutan is effective }\end{array}$ & & & & & \\
\hline
\end{tabular}




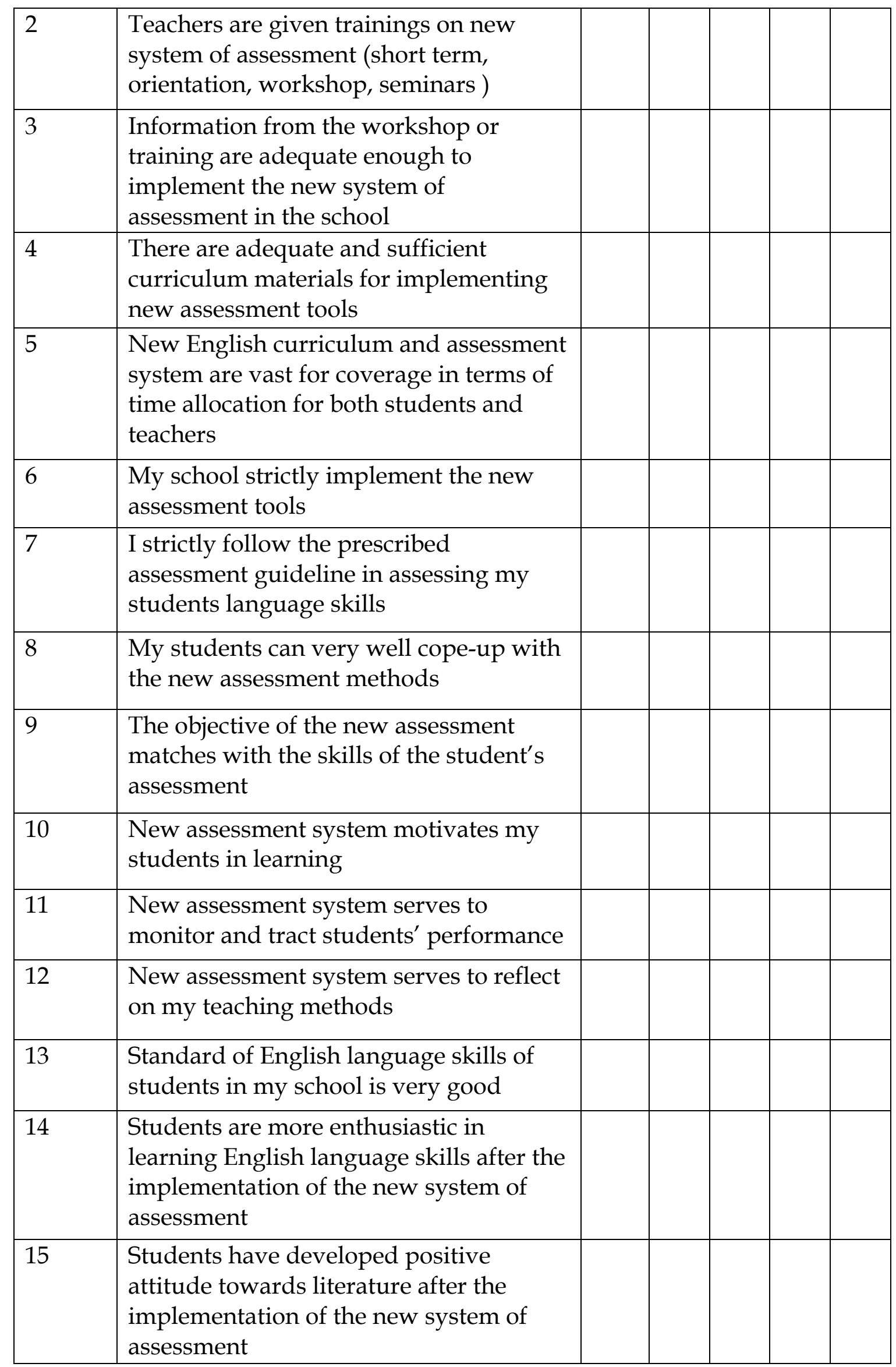




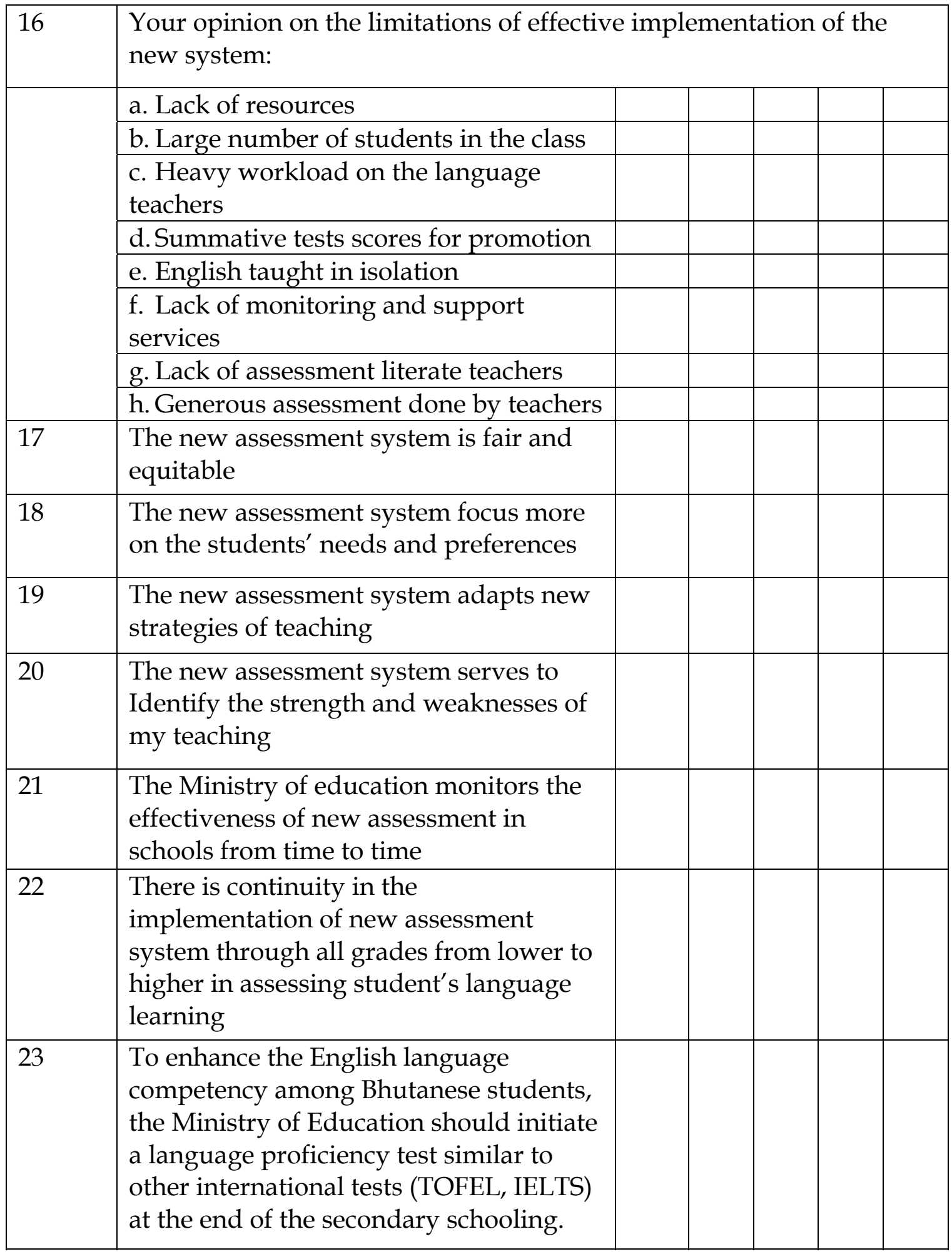

\section{Recommendation:}

What recommendations would you make for the success of attending positive washback effects of new English language assessment system on secondary schools of Bhutan? 
Thank You for your response!!!!!

\section{Appendix 4}

Interview guideline Questionnaire for students

Part A: Demographic information of the respondent

Age: ................. Class:

School:

Part B: Interview questionnaire

1. When did you graduate your secondary schooling?

2. How were you assessed in English language class?

3. Did you like it? Why or Why not?

4. How did it help you in your learning?

5. What do you expect in the assessment procedure?

6. What recommendation do you like to make for the effective implementation of such assessment system?

7. How were you assessed during your schooling before the new system?

8. What do you think of the test score being determinable factor for your promotion or detention?

9. What benefits do you see if there is an English language proficiency test at the end of secondary schooling?

\section{Recommendation:}

What recommendations would you make for the success of attending positive washback effects of new English language assessment system on secondary schools of Bhutan?

Thank You for your response!!!!!

Details of the Respondents (Teachers)

\section{Appendix 5}

\begin{tabular}{|l|l|l|l|}
\hline Respondents & Gender(M/F) & $\begin{array}{l}\text { Level of school } \\
\text { they work }\end{array}$ & $\begin{array}{l}\text { Qualification \& } \\
\text { Major }\end{array}$ \\
\hline Respondent 1 & F & MSS & B. Ed ( English) \\
\hline Respondent 2 & F & MSS & B. Ed ( English) \\
\hline
\end{tabular}




\begin{tabular}{|c|c|c|c|}
\hline Respondent 3 & F & HSS & BE. d ( English) \\
\hline Respondent 4 & M & MSS & B. Ed ( English) \\
\hline Respondent 5 & $\mathrm{~F}$ & MSS & B. Ed ( English) \\
\hline Respondent 6 & F & HSS & Not reflected \\
\hline Respondent 7 & $\mathrm{M}$ & HSS & B. Ed ( English) \\
\hline Respondent 8 & $\mathrm{M}$ & HSS & B. Ed ( English) \\
\hline Respondent 9 & $\mathrm{~F}$ & HSS & B. Ed ( English) \\
\hline Respondent 10 & M & HSS & M. Ed (English) \\
\hline Respondent 11 & $\mathrm{M}$ & MSS & B. Ed (Eng.) \\
\hline Respondent 12 & $\mathrm{~F}$ & HSS & M. Ed (English) \\
\hline Respondent 13 & F & MSS & Not reflected \\
\hline Respondent 14 & F & LSS & B. Ed (gen.) \\
\hline Respondent 15 & F & LSS & B. Ed (English) \\
\hline Respondent 16 & $\mathrm{~F}$ & LSS & Not reflected \\
\hline Respondent 17 & $\mathrm{~F}$ & HSS & Not reflected \\
\hline Respondent 18 & $\mathrm{~F}$ & HSS & M. Ed (English) \\
\hline Respondent 19 & $\mathrm{M}$ & HSS & B. Ed (English) \\
\hline Respondent 20 & $\mathrm{M}$ & MSS & BE. d (Geography) \\
\hline Respondent 21 & $\mathrm{M}$ & HSS & B. Ed (English) \\
\hline Respondent 22 & $\mathrm{~F}$ & MSS & Not reflected \\
\hline Respondent 23 & $\mathrm{~F}$ & MSS & Not reflected \\
\hline Respondent 24 & $\mathrm{~F}$ & HSS & B. Ed (Eng.) \\
\hline Respondent 25 & F & HSS & B. Ed \\
\hline Respondent 26 & F & MSS & B. Ed (Eng.) \\
\hline Respondent 27 & $\mathrm{M}$ & LSS & B. Ed (Math) \\
\hline Respondent 28 & F & LSS & B. Ed (Math) \\
\hline Respondent 29 & $\mathrm{~F}$ & MSS & Not reflected \\
\hline Respondent 30 & $\mathrm{M}$ & LSS & B. Ed \\
\hline Respondent 31 & $\mathrm{~F}$ & HSS & Not reflected \\
\hline Respondent 32 & $\mathrm{M}$ & HSS & Not reflected \\
\hline Respondent 33 & $\mathrm{M}$ & HSS & M. Ed (Eng.) \\
\hline Respondent 34 & $\mathrm{M}$ & HSS & Not reflected \\
\hline Respondent 35 & $\mathrm{~F}$ & HSS & B. Ed (Eng.) \\
\hline Respondent 36 & $\mathrm{~F}$ & LSS & B. Ed (Eng.) \\
\hline Respondent 37 & $\mathrm{~F}$ & HSS & M. Ed (Eng.) \\
\hline Respondent 38 & $\mathrm{M}$ & LSS & B. Ed (gen.) \\
\hline Respondent 39 & $\mathrm{~F}$ & MSS & B. Ed (Eng.) \\
\hline Respondent 40 & F & MSS & B. Ed (Geo.) \\
\hline
\end{tabular}




\begin{tabular}{|l|l|l|l|}
\hline Respondent 41 & M & HSS & Not reflected \\
\hline Respondent 42 & M & LSS & Not reflected \\
\hline Respondent 43 & M & LSS & B. Ed (Eng.) \\
\hline Respondent 44 & M & HSS & M. Ed (Eng.) \\
\hline Respondent 45 & M & MSS & Not reflected \\
\hline Respondent 46 & F & LSS & B. Ed (His.) \\
\hline Respondent 47 & F & LSS & B. Ed (Sci.) \\
\hline Respondent 48 & M & MSS & B. Ed \\
\hline Respondent 49 & F & LSS & B.Ed \\
\hline Respondent 50 & M & HSS & M. Ed (Eng.) \\
\hline Respondent 51 & M & HSS & Not reflected \\
\hline Respondent 52 & F & LSS & B. Ed (Eng.) \\
\hline Respondent 53 & F & LSS & Not reflected \\
\hline Respondent 54 & F & LSS & B. Ed (gen) \\
\hline Respondent 55 & M & MSS & B. Ed (gen) \\
\hline Respondent 56 & F & HSS & B. Ed (Eng.) \\
\hline & & & \\
\hline
\end{tabular}

